\title{
A multigene phylogeny of Olpidium and its implications for early fungal evolution
}

\author{
Satoshi Sekimoto ${ }^{1,3^{*}}, D^{\prime}$ Ann Rochon ${ }^{2}$, Jennifer E Long ${ }^{1,4}$, Jaclyn M Dee ${ }^{1}$ and Mary L Berbee ${ }^{1}$
}

\begin{abstract}
Background: From a common ancestor with animals, the earliest fungi inherited flagellated zoospores for dispersal in water. Terrestrial fungi lost all flagellated stages and reproduce instead with nonmotile spores. Olpidium virulentus (= Olpidium brassicae), a unicellular fungus parasitizing vascular plant root cells, seemed anomalous. Although Olpidium produces zoospores, in previous phylogenetic studies it appeared nested among the terrestrial fungi. Its position was based mainly on ribosomal gene sequences and was not strongly supported. Our goal in this study was to use amino acid sequences from four genes to reconstruct the branching order of the earlydiverging fungi with particular emphasis on the position of Olpidium.

Results: We concatenated sequences from the Ef-2, RPB1, RPB2 and actin loci for maximum likelihood and Bayesian analyses. In the resulting trees, Olpidium virulentus, $O$. bornovanus and non-flagellated terrestrial fungi formed a strongly supported clade. Topology tests rejected monophyly of the Olpidium species with any other clades of flagellated fungi. Placing Olpidium at the base of terrestrial fungi was also rejected. Within the terrestrial fungi, Olpidium formed a monophyletic group with the taxa traditionally classified in the phylum Zygomycota. Within Zygomycota, Mucoromycotina was robustly monophyletic. Although without bootstrap support,

Monoblepharidomycetes, a small class of zoosporic fungi, diverged from the basal node in Fungi. The zoosporic phylum Blastocladiomycota appeared as the sister group to the terrestrial fungi plus Olpidium.

Conclusions: This study provides strong support for Olpidium as the closest living flagellated relative of the terrestrial fungi. Appearing nested among hyphal fungi, Olpidium's unicellular thallus may have been derived from ancestral hyphae. Early in their evolution, terrestrial hyphal fungi may have reproduced with zoospores.
\end{abstract}

\section{Background}

Fungi in modern ecosystems are able to cause plant diseases, serve as mycorrhizal partners to plants, or decompose litter and woody debris using the tubular hyphae (filaments of walled cells) that make up fungal bodies. Hyphae use hydrostatic pressure to penetrate tough substrates such as soil and plant tissue, secreting enzymes across their chitinous cell walls to break down complex organic compounds into simple, diffusible molecules that are absorbed to nourish growth. An increasing body of phylogenetic evidence indicates that fungi, animals, and protists, such as nucleariid amoebae and Ichthyosporea, all share a close common ancestor [1-3]. This pattern implies that the original fungus-like

\footnotetext{
* Correspondence: ssekimoto@bama.ua.edu

'Department of Botany, 3529-6270 University Boulevard, University of British

Columbia, Vancouver, British Columbia, V6T 1 Z4 Canada

Full list of author information is available at the end of the article
}

organisms were not terrestrial and hyphal in their assimilative phase but were instead aquatic, flagellated and unicellular.

Fungi that have been classified in Zygomycota are phylogenetically important because in most studies, they appear as the first terrestrial fungi to have evolved from flagellated, aquatic ancestors. However, their backbone relationships remain largely unresolved. The lack of decisive evidence for monophyly has led to alternative classifications for Zygomycota [4]. Fungi once placed in Zygomycota are sometimes distributed among the Glomeromycota, comprising the arbuscular mycorrhizal fungi [5-7]; the Mucoromycotina; and "Zygomycota, unresolved", which includes animal or fungal symbionts or pathogens in the subphyla Entomophthoromycotina, Zoopagomycotina, and Kickxellomycotina. For convenience in the text, we will continue to apply 'Zygomycota'
C Biomed Central 
to these terrestrial, non-flagellated fungi including Glomeromycota and Mucoromycotina.

In terms of evolutionary inference, some of the first molecular phylogenies from ribosomal gene sequences specified, probably incorrectly, that two clades of terrestrial Zygomycota evolved convergently from flagellated, aquatic ancestors. Early studies showed that the flagellated Blastocladiomycota grouped with terrestrial Zygomycota including Rhizopus, and the flagellated Chytridiomycota grouped with the terrestrial Zygomycota Basidiobolus [8-11]. This pattern was likely an artifact of long-branch attraction and it is contradicted by more recent analyses including more taxa or different loci. More recently, a phylogeny of the amino acid sequences of RPB1 showed Basidiobolus grouping with other Zygomycota rather than with Chytridiomycota [12]; Zygomycota appear monophyletic in analysis of RPB1 and RPB2 [13]; and Zygomycota are paraphyletic in a multi-locus, phylogenomic study [14].

Against the background of recent support for a single origin of nonflagellated terrestrial fungi (Zygomycota plus Dikarya), James et al. $[5,15]$ found yet another possible example of convergent loss of flagella. As the first to include the zoospore-producing Olpidium virulentus (= Olpidium brassicae) [16] in their analyses, James et al. [5] were surprised to find that this flagellated fungus clustered with Basidiobolus, although without statistical support. Olpidium and Basidiobolus were further nested among terrestrial fungi with strong support from both posterior probabilities and likelihood bootstrap proportions. To explain the nesting of Olpidium within the non-flagellated fungi required 2-4 losses of flagella [5]. This finding of a flagellate within the terrestrial clade was no obvious artifact of long-branch attraction. The James et al. [5] study included a rich sampling of available basal fungal lineages and neither Olpidium nor Basidiobolus had particularly long-branch lengths.

Olpidium is however a challenging genus and it seemed possible that its apparent phylogenetic position was influenced by missing data. Several species, including Olpidium virulentus and Olpidium bornovanus, are biotrophic plant pathogens, unable to grow except as unicellular thalli that develop embedded inside living plant root cells [17-19]. At maturity, zoospores with single posterior flagella are liberated from the root cell through spore exit tubes [17] (Figure 1). Because they are biotrophic, relatively pure Olpidium DNA can only be harvested from zoospores. Washing roots with mature sporangia in distilled water triggers zoospore release. However, the zoospore suspension is not axenic. Olpidium DNA sequences are mostly too divergent to be amplified with universal fungal primers. As a result of these difficulties, James et al. [5] were only able to analyze one protein coding gene sequence $(R P B 1)$ in

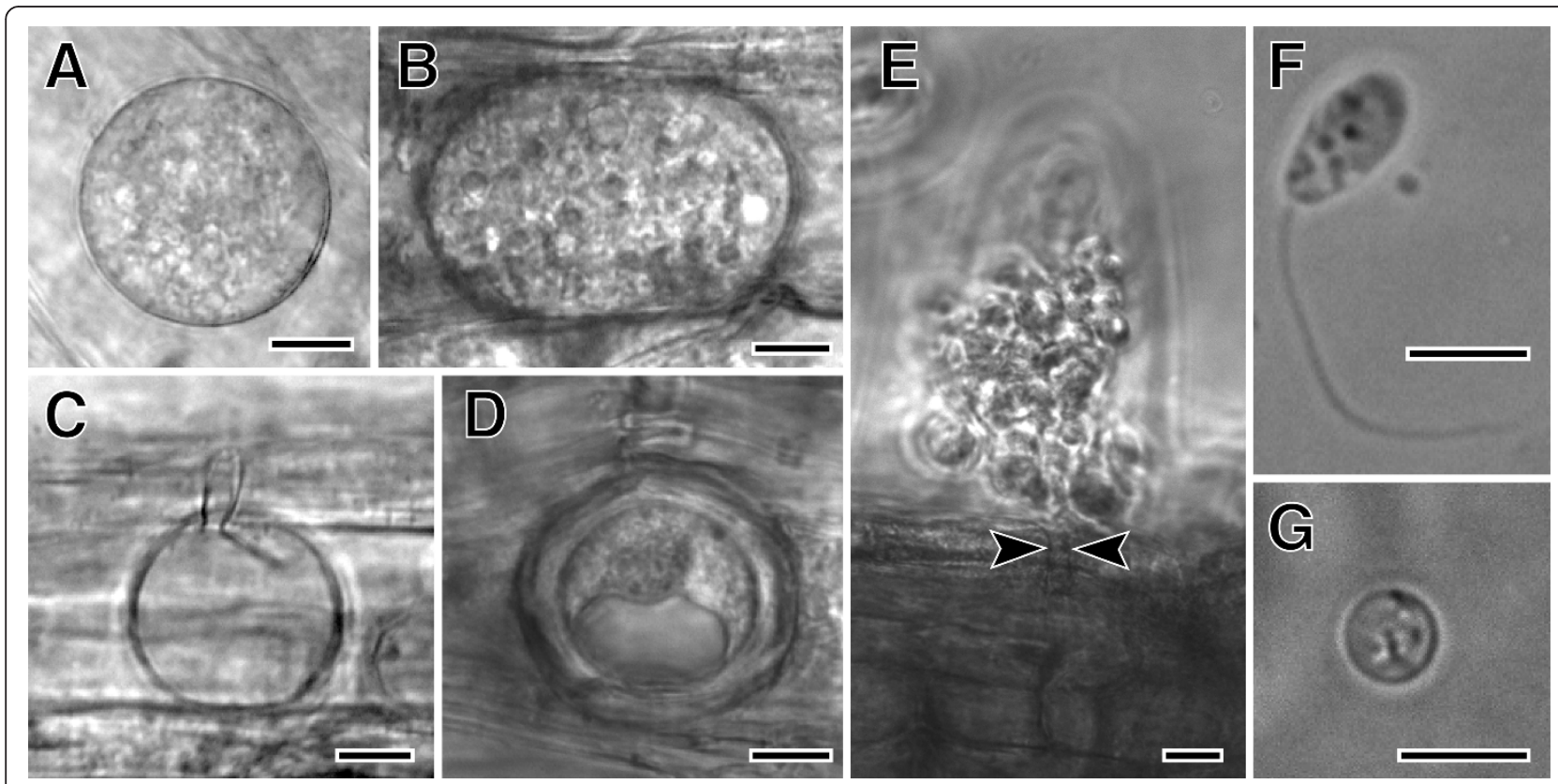

Figure 1 Olpidium bornovanus, a unicellular fungus, is an obligate parasite of plants that reproduces with flagellated, swimming zoospores. A-B. Vegetative unicellular thalli in cucumber root cells. Thalli differentiate into sporangia with zoospores, or into resting spores. C. An empty sporangium, after zoospore release. D. A thick-walled resting spore. E. Zoospores being released from a sporangium, showing the sporangium exit tube (arrowheads). F. A swimming zoospore with a single posterior flagellum. G. An encysted zoospore. Bars: A-E = $10 \mu m ; F, G$ $=5 \mu \mathrm{m}$. 
addition to ribosomal genes, from only one Olpidium species.

Our objectives in this study included rigorous testing of the phylogenetic position of Olpidium and resolving the relationships among clades in the Zygomycota and the flagellated fungi, with the overall goal of improving understanding of the early evolution of Fungi. We used genes for four proteins, translation elongation factor 2 $(E f-2)$, RNA polymerase II largest subunit (RPB1), RNA polymerase II second largest subunit (RPB2), and actin. Although $E f-2$ genes have proven useful in other eukaryotic lineages [20], this study represents their first use for the deep phylogeny of Fungi. Olpidium, if nested within Zygomycota, becomes a key organism for reconstructing the trail of how terrestrial fungi lost their flagella and colonized land.

\section{Results}

\section{Overall phylogenetic analyses of the kingdom Fungi}

The kingdom Fungi formed a robust clade in maximum likelihood and Bayesian analysis from the dataset of concatenated amino acid sequences from four genes (Figure 2). The terrestrial fungi plus the flagellated fungi Olpidium virulentus and O. bornovanus formed a monophyletic group excluding all other flagellated fungi with $95 \%$ bootstrap support and a posterior probability of 1.0 (Figure 2). Topology tests rejected all alternative trees that constrained the Olpidium species to cluster with other groups of flagellated fungi (Table 1). A clade including the Zygomycota plus Olpidium was also monophyletic with $68 \%$ bootstrap support from likelihood and a posterior probability of 0.98 (Figure 2 ). In our analysis, terrestrial fungi were divided between the monophyletic Zygomycota plus Olpidium, and the Dikarya (= Ascomycota plus Basidiomycota). The Zygomycota included two well-supported groups: Mucoromycotina and Glomeromycota. The Zygomycota also included "Zygomycota, unresolved" (Figure 2), a weakly supported clade consisting largely of animal or fungal symbionts or pathogens [4-6]. "Zygomycota, unresolved" also included Olpidium. If any group within Zygomycota were the sister group to Olpidium, it was not clear from our phylogenies. The two species that clustered most closely with Olpidium in the Bayesian analysis, Piptocephalis corymbifera and Rhopalomyces elegans, had long-branches (data not shown), were missing data from two loci, and did not cluster with Olpidium in the likelihood analysis (Figure 2). In Approximately Unbiased tree topology tests, uniting Olpidium with Glomeromycota could not be rejected at the p-value of $<0.05$ (Table 1 ). In the more conservative weighted Shimodaira-Hasegawa tests, uniting Olpidium with Mucoromycotina and with Dikarya could not be rejected either (Table 1). These analyses suggest that Olpidium is part of the terrestrial fungi, but leave open the possibility that it may be the sister taxon to the Dikarya, or sister to one of the basal clades within Zygomycota.

Concerning the other flagellated fungi, the concatenated dataset provided strong support for the monophyly of the Blastocladiomycota, the "core chytrid clade", and the Monoblepharidomycetes. Although support was low, the flagellated fungi form a paraphyletic assemblage, with Monoblepharidomycetes diverging first, then the Neocallimastigomycota, the "core chytrid clade," and finally, the Blastocladiomycota as the sister group to the terrestrial fungi. Tree topology tests did not reject any of the alternative possible patterns of relationships among the three basal clades of flagellated fungi (Monoblepharidomycetes, Neocallimastigomycota, and "core chytrid clade") (data not shown).

Analyzed separately, individual gene trees did not resolve branching order of basal fungal clades with significant bootstrap support (Figure S1a-S1d in Additional file 1). However, the Ef-2 likelihood tree showed Olpidium in "Zygomycota, unresolved" with 56\% support and all the genes except actin placed Olpidium with members of "Zygomycota, unresolved". Overall, actin provided less phylogenetic information than the other genes due to its low substitution rates (note the much longer scale bar relative to 0.1 substitutions, Figure S1d) compared with scale bars for other single genes (Figure S1a-S1c) for phylogenetic analysis.

\section{Olpidium sequences}

Because Olpidium cultures were not axenic, we had to use phylogenetic concordance as a criterion for testing whether or not their DNA sequences could be from contaminants. Reassuringly, in a maximum likelihood tree from concatenated data (Figure 2), sequences of the two Olpidium species formed a robust clade among other fungi with $100 \%$ bootstrap support. As expected, they grouped among the Zygomycota, consistent with results from James et al. [5]. Sequences from both species also clustered together in individual gene trees whenever both species were included in the analysis (Figure S1a, S1b, and S1d in Additional file 1). The $R P B 1$ gene sequence obtained from our O.virulentus (GenBank AB644405) was almost identical to O.virulentus isolate used in James et al. (GenBank DQ294609) [5]. As an additional assay for possible contamination, we amplified the SSU rRNA gene region from DNA extracts by PCR with eukaryotic-universal SSU primers [SR1 (5'-TACCTGGTTGATCCTGCCAG-3') and SR12 (5'-CCTTCCGCAGGTTCACCTAC-3')], then sequenced amplicons directly. We found the Olpidium SSU rRNA gene region in our extracts and we did not detect the host plant or any other sequences (data not shown). 


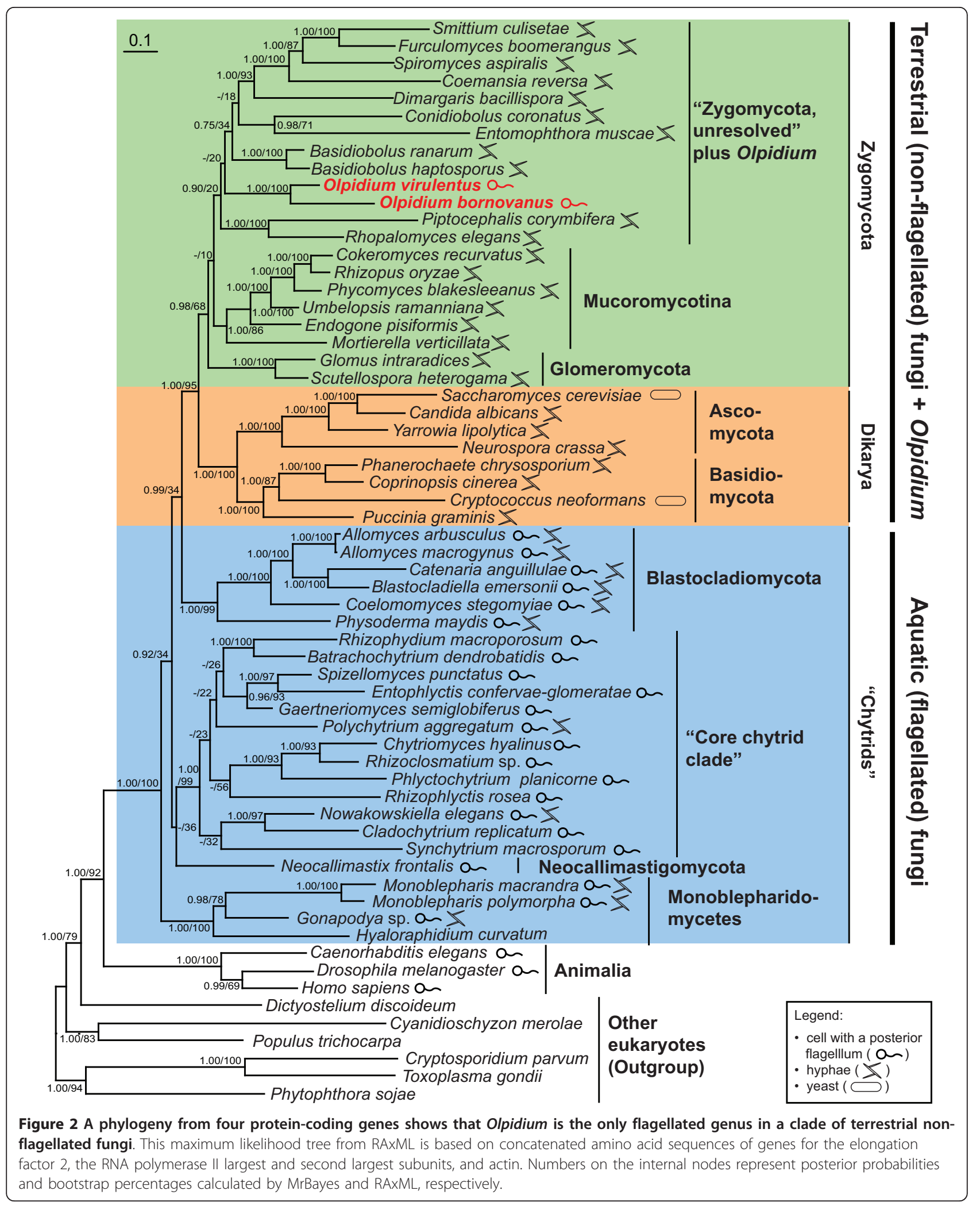


Table 1 The only phylogenetic positions of Olpidium that could not be rejected by either the weighted ShimodairaHasegawa (wSH) or the Approximately Unbiased (AU) tests were within the Zygomycota.

\begin{tabular}{|c|c|c|c|c|}
\hline Tree & Constraint & $\Delta \operatorname{lnL}$ & $A U^{1}$ & $\mathrm{wSH}^{1}$ \\
\hline 1 & Olpidium united with "Zygomycota, unresolved" (Best tree; Figure 2) & 0.0 & 0.896 & 0.995 \\
\hline 2 & Olpidium united with Glomeromycota in Zygomycota & 19.8 & 0.208 & 0.619 \\
\hline 3 & Olpidium united with Mucoromycotina in Zygomycota & 42.3 & $0.013^{*}$ & 0.087 \\
\hline 4 & Olpidium united with Dikarya & 65.7 & $0.011^{*}$ & 0.058 \\
\hline 5 & Olpidium sister to all terrestrial fungi & 80.8 & $0.000^{* *}$ & $0.010^{*}$ \\
\hline 6 & Olpidium united with Blastocladiomycota & 148.4 & $0.002^{* *}$ & $0.004^{* *}$ \\
\hline 7 & Olpidium sister to all other fungi & 148.7 & $0.005^{* *}$ & $0.008^{* *}$ \\
\hline 8 & Olpidium sister to all terrestrial fungi and Blastocladiomycota & 154.6 & $0.000^{* *}$ & $0.000^{* *}$ \\
\hline 9 & Olpidium united with Neocallimastigomycota & 174.1 & $0.004^{* *}$ & $0.013^{*}$ \\
\hline 10 & Olpidium united with Monoblepharidomycetes & 203.6 & $0.000^{* *}$ & $0.000^{* *}$ \\
\hline 11 & Olpidium united with "Core chytrid clade" & 233.6 & $0.000^{* *}$ & $0.000^{* *}$ \\
\hline
\end{tabular}

${ }^{1} \mathrm{AU}$, Approximately Unbiased; wSH, weighted Shimodaira-Hasegawa test. The constrained tree was significantly worse than the best tree (Figure 2 ) at $\mathrm{P}<0.05^{*}$ or $\mathrm{P}<0.01^{* *}$.

This result suggested that Olpidium DNA predominated in our extracts.

However, along with the Olpidium sequences that clustered, as expected, in the fungi, we also found additional, aberrant sequences for $E f-2, R P B 2$, and actin (Figure S1a, S1c, and S1d in Additional file 1). These sequences did not match common laboratory contaminants. From the $E f-2$ dataset, in addition to the set of Olpidium sequences that clustered as expected, within "Zygomycota, unresolved," a pair of sequences clustered with the slime mold Dictyostelium discoideum (Figure $\mathrm{S} 1 \mathrm{a})$. From the RPB2 dataset, one O. bornovanus sequence clustered with the zygomycete Conidiobolus coronatus and the other with $D$. discoideum (Figure S1c). In the actin dataset, we detected two O. virulentus and four O. bornovanus actin-like sequences (Figure S1d). One pair of sequences from Olpidium species clustered together in Fungi, but the other four sequences clustered with non-fungal taxa (Figure S1d). The aberrant sequences could be divergent paralogs or genes gained through horizontal gene transfer, and we cannot even rule out contamination as their source. We deleted those aberrant sequences (Figure S1a, S1c, S1d) from our four-protein dataset used in the likelihood and Bayesian analyses (Figure 2, S2).

\section{Discussion}

Phylogenetic position of Olpidium

Our likelihood and Bayesian analyses strongly suggest that Olpidium virulentus and O. bornovanus are more closely related to terrestrial fungi than to other clades of flagellated fungi. Olpidium has typical "core chytrid" characters including a single endobiotic sporangium producing zoospores having a single posterior flagellum. It shares no obvious morphological characters with any clade of terrestrial fungi. Whether Olpidium and terrestrial fungi share biochemical characters, such as enzyme systems for entry into plant cell walls, remains to be seen.

None of the other Zygomycota genera are close to Olpidium, based on the tendency of Olpidium to cluster with different genera in different analyses, without support. This lack of resolution may be yet another longbranch attraction problem. Adding more species of Olpidium to a phylogeny would contribute to breaking up the Olpidium branch and would allow reconstruction of the ancestral traits of Olpidium. However, most of the $\sim 50$ Olpidium species are difficult to obtain. We were able to include $O$. virulentus and $O$. bornovanus in this study only because Rochon and colleagues grow them routinely to serve as vectors for experimental transmission of viral diseases of plants [21,22]. Other species of evolutionary interest from other hosts (fungi, moss protonemata, microscopic animals, or algae) would have to be isolated from nature and cultured along with their hosts. As shown in other morphologically simple but diverse fungal genera, e.g., Rhizophydium [23], Olpidium is likely not monophyletic. Species differ in cell size (depending on the size of the host cell), shape (spherical to ovoid, irregular, tubular or elongate), and other morphological characters (resting spore morphology, number of spore exit tubes etc.). Ultrastructure also varies from species to species. Olpidium pendulum perhaps belongs in a genus separate from $O$. virulentus and O. bornovanus (as a synonym of O. cucurbitacearum) [24-31]. Some of the other species might belong in the same clade as our two plant parasitic Olpidium, while others will likely fall out with the "core chytrids" instead.

\section{Terrestrial fungal relationships-a classical phylogenetic challenge?}

Conflicts among phylogenies from different datasets suggest that as fungi first colonized land, at least five 
basal lineages (Mucoromycotina, Glomeromycota, "Zygomycota, unresolved", Dikarya, Olpidium) radiated rapidly and then evolved independently by different rates and modes of substitution. A succession of researchers have noted and attempted to solve the problem of variation in rates and modes with various analytical strategies. Tanabe et al. [32] pointed out the ribosomal substitution rates varied dramatically in relative rate tests and recommended relying more heavily on RPB1, which showed less rate variation. Voigt and Wöstemeyer [33] used logdet methods to overcome biases resulting from lineage-specific variation in nucleotide composition to estimate distances. Liu et al. [14] applied huge amounts of sequence, analyzing 40,925 amino acids with a substitution model intended to minimize long-branch attraction problems. In their ribosomal gene phylogeny, White et al. [6] included an excellent sampling of taxa representing most known Zygomycota lineages, including many species that have not appeared in other studies because they are difficult to grow.

No aspect of basal branching order for these taxa receives consistent support across studies. The clade corresponding to the traditional Zygomycota from our study and from Liu et al.'s RPB1 and RPB2 amino acid phylogenies [13] does not appear in analyses consisting largely or entirely of ribosomal DNA sequences $[5,6,15]$ or of actin plus Ef-1 alpha [33,34]. It is also missing from a phylogenomic study of nuclear genes [14] where Mucoromycotina is sister to Dikarya. Our analyses show Mortierella verticillata as part of Mucoromycotina. This relationship was supported strongly in our analysis of concatenated data; it was evident in our Ef-2 and RPB1 gene trees, and it is consistent with some traditional classifications schemes based on morphology [35]. Liu et al. [14], however, showed Mortierella diverging much earlier (although with limited support) as one of the three Zygomycota lineages paraphyletic to Mucoromycotina plus Dikarya. Although the Liu et al. [14] study had a great deal of data per taxon and an appropriate model of evolution, the number of genomes available for analysis may still be too small to capture branching order with statistical support. As a result, in Liu et al.'s [14] study, long-branch attraction or other kinds of systematic error may have been responsible for pulling Mortierella away from its closest relatives. In contrast, our phylogenies have good representation of lineages but data from only four loci, and our inability to reject alternative topologies in weighted Shimodaira-Hasegawa and Approximately Unbiased tests reflects the need for more data per taxon. Resolution of the relationships among early fungi joins the resolution of relationships among the first animals and among seed plants as a difficult phylogenetic problem.

\section{Phylogenetic age of origin of fungal hyphae}

Branching order among early-diverging fungal groups has been assumed to involve progressive elaboration of thread-like hyphal systems [2], from ancestors, which like most "core chytrids," had unicellular thalli. Beyond the Fungi, the oomycetes, chromistan fungus-like protists, provide an example of convergent origin of hyphae. Oomycete thalli range from single cells to well-defined mycelia [19]. Recent phylogenetic studies have indicated that the ancestral oomycetes might have been unicellular endoparasites of marine organisms that later gave rise to hyphal species. Of the hyphal oomycete species, some remained aquatic, while others invaded land [36]. Ability to form hyphae may have been an important character that allowed early oomycetes as well as early Fungi to poke, penetrate and explore to find terrestrial food that may have been patchy in its distribution.

As in the oomycetes, hyphae may have evolved in fungi even before they colonized land. Most of the known Monoblepharidomycetes are hyphal, and they diverged at or near the base of the Fungi. The Blastocladiomycota, the aquatic sister clade to the terrestrial fungi $[5,6,14]$, also includes genera with well-developed mycelia. Since its relatives are hyphal, Olpidium's unicellular thallus is perhaps an adaptation to parasitism and a reduction from a hyphal ancestor. On the other hand, finding Olpidium nested among the terrestrial clades implies that fungi on land initially had flagellated spores. Eukaryotic flagella are complex structures that would have been unlikely to evolve repeatedly, and so multiple losses of flagella were far more likely than a convergent gain in Olpidium. As in early terrestrial animals and plants, early terrestrial fungi retained a motile unicellular phase.

We reluctantly excluded two interesting basal fungal lineages, microsporidia and Rozella [5], from our analyses. Microsporidia, obligate intracellular pathogens of animals, have unusual, highly divergent genes [37]. Conserved synteny among the microsporidia and the zygomycotan Phycomyces blakesleeanus and Rhizopus oryzae has been used to suggest that the microsporidia may be related to Mucoromycotina [38], an interpretation contested by Koestler and Ebersberger [39]. Sequences from microsporidia are difficult to align and a source of artifacts involving long-branch attraction. It seemed more likely that microsporidia would obscure phylogenetic signal in our dataset than that our analysis would correctly resolve their relationships.

Rozella allomycis is a unicellular obligate endoparasite of Allomyces arbusculus, another fungus [40]. James et al. [5] found Rozella allomycis to group with microsporidia at the base of Fungi. Unfortunately, the only known living culture of Rozella had died before our study, so we were unable to contribute new data for the genus. 
Rozella is basal in Fungi in our RPB1 and RPB2 individual trees. This could be its correct phylogenetic position but it could also reflect long-branch attraction (Figure S1b, S1c, in Additional file 1). Adding Rozella to the analysis caused relationships among the other flagellated fungi to shift (Figure S2 in Additional file 2). Our tree topology test did not rule out most possible topologies for the positioning of Rozella with other fungal lineages (Table S1, in Additional file 2). Uncertain about the reason for the behaviour of Rozella, we show the consequences of including it in the supplemental file (Figure S2) but excluded the taxon from the analyses in Figure 2.

\section{Conclusions}

Even with analysis of amino acid sequences from four protein-coding loci, and from all available early-diverging lineages, the resolution of branching order in the deepest parts of kingdom Fungi remains uncertain. Instead of converging on a single solution, recent studies of early fungi have produced conflicting phylogenies. Our trees showed the zoosporic Monoblepharidomycetes to be sister to all other fungi, the zoosporic Blastocladiomycota to be sister to terrestrial fungi, and the Zygomycota to be monophyletic. These relationships require further testing through phylogenomic analysis and comprehensive taxon sampling.

Our study provided the strongest support to date for the monophyletic group that includes two zoosporic Olpidium species together with all of the non-flagellated, terrestrial fungi. Here, the results from our study and others are congruent. If its nested position among hyphal fungi is correct, the unicellular thallus of Olpidium may have evolved by reduction from hyphae, contradicting an intuitive expectation that the smaller structure would predate the larger one. Swimming zoospores that germinated and grew as hyphae may have been the fungal analogues of amphibians that made the earliest evolutionary forays into drier environments.

\section{Methods}

Fungal strains, DNA and RNA extraction, PCR amplification and sequencing

Table S2 (in Additional file 3) lists fungal strains sequenced in this study. All zygomycetes were maintained on potato dextrose agar medium (PDA: Difco Grade, Becton, Dickinson and Company, MD, USA), or PDA plus $0.5 \%$ yeast extract medium at ambient temperature, as described in O'Donnell [41]. All chytrids except the two Olpidium strains were maintained on PmTG agar medium [42]: 1g peptonized milk, 1g tryptone, $5 \mathrm{~g}$ glucose, $8 \mathrm{~g}$ agar, and 1litre of distilled water) at ambient temperature. Olpidium bornovanus was maintained on cucumber roots (C. sativis cv. Poinsette 76), and O. virulentus was maintained on lettuce roots ( $\mathrm{Lac}$ tuca sativa $\mathrm{cv}$. White Boston) as described by Campbell et al. [43]. The full length of the internal transcribed spacer (ITS) regions (between the $18 \mathrm{~S}, 5.8 \mathrm{~S}$ and $28 \mathrm{~S}$ ribosomal $R N A$ genes) of our $O$. virulentus strain was sequenced for species identification, and it had 100\% nucleotide similarity with that of $O$. virulentus strain GBR1 (GenBank no. AY373011) [16,44]. Ef-2 gene sequences of two Olpidium species and RPB2 gene sequences of $O$. bornovanus were obtained from total RNA, and all other sequences obtained in this study were from total genomic DNA. For the RNA and DNA extraction from two Olpidium strains, we used TRIzol Reagent following the procedure outlined by Invitrogen (Mississauga, Ontario, Canada). Prior to DNA and RNA extraction the Olpidium zoospores were pelleted from root washings at $2,700 \times \mathrm{g}$ for 7 minutes. Total genomic DNA from cultured strains was extracted using a DNeasy Plant Mini Kit (Qiagen, Mississauga, Ontario, Canada), following the manufacturer's protocol.

Primers were designed in this study, or taken from James et al. [5], or Hoffmann et al. [45] (Table S2, Additional file 3 Table S3, Additional file 4). We amplified the partial genes for eukaryotic translation elongation factor 2 (Ef-2), RNA polymerase II largest subunit (RPB1), RNA polymerase II second largest subunit (RPB2), and actin using $0.5 \mu \mathrm{M}$ concentrations of primers, two to five $\mu$ l of genomic DNA solution, and PureTaq ${ }^{\mathrm{TM}}$ Ready-To-Go ${ }^{\mathrm{TM}}$ PCR beads (Amersham Biosciences, Piscataway, NJ, USA) following the manufacturer's protocol. Total PCR reaction volume was 25 $\mu \mathrm{l}$, and cycling parameters were: initial denaturation (5 min, $\left.94^{\circ} \mathrm{C}\right)$, followed by 40 cycles $\left(94^{\circ} \mathrm{C}, 10 \mathrm{~s} ; 50-65^{\circ} \mathrm{C}\right.$, $20 \mathrm{~s} ; 72^{\circ} \mathrm{C}$ for $30 \mathrm{~s}$ plus 4 additional seconds per cycle), and then a final extension at $72^{\circ} \mathrm{C}$ for $7 \mathrm{~min}$. RT-PCR was conducted using SuperScript ${ }^{\mathrm{TM}}$ One-Step RT-PCR with Platinum ${ }^{\circledR}$ Taq (Invitrogen) following manufacturer's protocol. The total $25 \mu \mathrm{l}$ reaction volume of RTPCR, contained $0.2 \mu \mathrm{M}$ concentrations of primers, $1 \mu \mathrm{l}$ of total RNA solution, $0.5 \mu$ l of RNaseOUT ${ }^{\circledR}$ Recombinant Ribonuclease Inhibitor (Invitrogen), $12.5 \mu \mathrm{l}$ of $2 \times$ Reaction Mix, and $1.0 \mu \mathrm{l}$ of RT/Platinum ${ }^{\mathbb{B}}$ Taq Mix. Cycling parameters were: reverse transcription (32 min, $55^{\circ} \mathrm{C}$ ) and initial denaturation $\left(5 \mathrm{~min}, 94^{\circ} \mathrm{C}\right)$, followed by 40 cycles $\left(94^{\circ} \mathrm{C}, 15 \mathrm{~s} ; 55^{\circ} \mathrm{C}, 30 \mathrm{~s} ; 68^{\circ} \mathrm{C}\right.$ for $30 \mathrm{~s}$ plus 4 additional seconds per cycle), and then a final extension at $68^{\circ} \mathrm{C}$ for $10 \mathrm{~min}$. PCR products were then purified with EtOH precipitation $(20 \mu \mathrm{l} \mathrm{PCR}$ products, $2 \mu \mathrm{l} 3 \mathrm{M}$ sodium acetate ( $\mathrm{pH} 4.5), 50 \mu \mathrm{l} 95 \%$ ethanol; $15 \mathrm{~min}$ spin and rinse with $70 \%$ ethanol twice, resuspended in $20 \mu \mathrm{l}$ water), or cloned with TOPO ${ }^{\circledR}$ TA Cloning kit (Invitrogen) following the manufacturer's protocol. Products were then sequenced with BigDye Terminator v3.1 Cycle Sequencing Kit on a Applied Biosystems 3730S 
48-capillary sequencer (Applied Biosystems, Foster City, CA, USA) at NAPS Unit, MSL, University of British Columbia [accession numbers; DDBJ:AB609150 AB609186, AB625456, and GenBank:HM117701 HM117719; Table S4 in Additional file 5].

\section{Sequence alignments}

DNA sequences were assembled and edited using the software Se-Al v2.0a11 [46]. Also using Se-Al, sequences were manually added to $R P B 1$ and $R P B 2$ amino acid alignments of James et al. [5] or to the actin alignment of Voigt \& Wöstemeyer [33]. Introns, ambiguously aligned positions and gaps were excluded from both analyses. Alignments have been accessioned in TreeBASE (S11208, http://purl.org/phylo/treebase/phylows/ study/TB2:S11208).

\section{Molecular phylogenetic analysis}

Phylogenetic relationships were inferred from maximum likelihood and Bayesian methods, and all four protein datasets were combined and used for both analyses (Figure 2). ProtTest version 2.4 [47] estimated that the bestfit model of protein evolution for each of the individual alignment datasets was the LG model, with site-to-site rate variation approximated with a gamma distribution (G) and an estimated proportion of invariable sites (I), and with empirical base frequencies (F) $(\mathrm{LG}+\mathrm{G}+\mathrm{I}+\mathrm{F})$. For likelihood, we used RAxML version 7.0.3 [48], with the $\mathrm{LG}+\mathrm{G}+\mathrm{I}+\mathrm{F}$ model and 600 replicate searches. We used 1000 likelihood bootstrap replicates with the rapid bootstrapping algorithm in RAxML version 7.2.7 with the $\mathrm{LG}+\mathrm{G}+\mathrm{F}$ model conducted on CIPRES Science Gateway Web server (on RAxML-HPC2 on Abe 7.2.7) [49]. For Bayesian posterior probabilities for branch nodes, we used MrBayes version 3.1.2 [50] on Parallel MrBayes Web Server at the BioHPC compute cluster at CBSU (http://biohpc.org/), with 1,713,600 generations, sampling trees every 100 generations, and discarding the first 5000 trees as a burnin. Convergence was evaluated from running two independent chains. The effective sample size was $>288.3$ and 325.2, estimated by Tracer v1.5 [51]. Each of the four of individual protein data sets was analyzed with likelihood as explained above Figure S1a-S1d (in Additional file 1).

\section{Tree topology tests}

To compare alternative phylogenetic positions for Olpidium, we used the Approximately Unbiased test and the weighted Shimodaira-Hasegawa test [52,53], both implemented by CONSEL v0.20 [54], using the site-wise likelihood values estimated in PAUP v.4.0b10 [55]. Each constrained tree was based on an initial guide tree with a single internal branch, generated in MacClade version 4.08 [56] or in Mesquite version 2.75 [57] (Additional file 6). The most likely tree (Additional file 6), given each constraint, was found using 50 search replicates in RAxML version 7.2.8 with the $\mathrm{LG}+\mathrm{G}+\mathrm{F}$ model conducted on CIPRES Science Gateway Web server (on RAxML-HPC2 on TeraGrid) [49].

\section{Additional material}

Additional file 1: Figure S1. The phylogeny of the kingdom Fungi
based on likelihood analysis of amino acid sequences from single
genes. Figure S1a, elongation factor 2 tree; Figure S1b, RNA
polymerase II largest subunit tree; Figure S1c, RNA polymerase II
second largest subunit tree; Figure S1d, actin tree.
Additional file 2: Figure S2 and Table S1. Figure S2. The phylogeny
of the kingdom Fungi, including Rozella allomycis, based on
likelihood analysis of amino acid sequences of four concatenated
protein-encoding genes. Table S1. Tree topology tests showing that
most of the alternative phylogenetic positions of Rozella could not
be rejected.
Additional file 3: Table S2. Species sequenced in this study,
including voucher numbers and primer sets used.
Additional file 4: Table S3. Primers used in this study.
Additional file 5: Table S4. GenBank accession numbers of
sequences used in this study.
Additional file 6: The initial guide trees with a single internal
branch, and the most likely trees given the constraint, that we used
for the tree topology tests in Table 1. All trees are in Newick
format.

\section{Acknowledgements}

This research was financially supported by the US National Science Foundation Systematics and Population Biology/Assembling the Tree of Life Program through the collaborative research grant titled 'Assembling the Fungal Tree of Life' (DEB-0732984), and through a Natural Sciences and Engineering Research Council of Canada Discovery grant to Berbee. For computing support, we thank David Carmean (Simon Fraser University, Canada); Joseph Spatafora and Christopher Sullivan (Oregon State University, USA); and the Oregon State University Center for Genome Research and Biocomputing. The cultures were kindly supplied by the following researchers and culture collections; Kerry O'Donnell (NCAUR-ARS-USDA, USA) Joyce E. Longcore (University of Maine, USA), Peter M. Letcher (University of Alabama, USA), UC Berkeley Microgarden (USA), Canadian Collection of Fungal Cultures (CCFC, Canada), Sammlung von Algenkulturen Göttingen (SAG, Germany), and UBC Herbarium, University of British Columbia. Authors thank Bernard Ball (Lutzoni Lab, Duke University, USA) for sharing unpublished Ef-2 gene primer sequences.

\section{Author details}

'Department of Botany, 3529-6270 University Boulevard, University of British Columbia, Vancouver, British Columbia, V6T 1 Z4 Canada. ${ }^{2}$ Agriculture and Agri-Food Canada, Pacific Agri-Food Research Centre, Summerland, British Columbia, VOH 1 Z0 Canada. ${ }^{3}$ Department of Biological Sciences, The University of Alabama, Tuscaloosa, AL 35487, USA. ${ }^{4}$ Department of Biology, University of Victoria, P.O. Box 3020 - Station CSC, Victoria, British Columbia, V8W 3N5 Canada.

\section{Authors' contributions}

SS and JMD sequenced Ef-2 gene sequences. SS sequenced RPB1 and RPB2 gene sequences. JEL sequenced and constructed actin data set. SS constructed Ef-2, RPB1, and RPB2 dataset, and prepared the manuscript. DR prepared and provided DNA and RNA extracts from two Olpidium species. SS and MLB conducted the phylogenetic analysis. MLB participated in the design of study. All authors joined in reading, editing and approving the manuscript. 
Received: 28 April 2011 Accepted: 15 November 2011

Published: 15 November 2011

\section{References}

1. Ruiz-Trillo I, Burger G, Holland PWH, King N, Lang BF, Roger AJ, Gray MW: The origins of multicellularity: a multi-taxon genome initiative. Trends in Genetics 2007, 23(3):113-118.

2. Stajich JE, Berbee ML, Blackwell M, Hibbett DS, James TY, Spatafora JW, Taylor JW: The Fungi. Current Biology 2009, 19(18):R840-R845.

3. Wainright PO, Hinkle G, Sogin ML, Stickel SK: Monophyletic origins of the Metazoa: an evolutionary link with Fungi. Science 1993, 260(5106):340-342.

4. Hibbett DS, Binder M, Bischoff JF, Blackwell M, Cannon PF, Eriksson OE, Huhndorf S, James T, Kirk PM, Lucking R, et al: A higher-level phylogenetic classification of the Fungi. Mycological Research 2007, 111:509-547.

5. James TY, Kauff F, Schoch CL, Matheny PB, Hofstetter V, Cox CJ, Celio G, Gueidan C, Fraker E, Miadlikowska J, et al: Reconstructing the early evolution of Fungi using a six-gene phylogeny. Nature 2006, 443(7113):818-822

6. White MM, James TY, O'Donnell K, Cafaro MJ, Tanabe Y, Sugiyama J: Phylogeny of the Zygomycota based on nuclear ribosomal sequence data. Mycologia 2006, 98(6):872-884

7. Schüßler A, Schwarzott D, Walker C: A new fungal phylum, the Glomeromycota: phylogeny and evolution. Mycological Research 2001, 105:1413-1421.

8. Nagahama T, Sato H, Shimazu M, Sugiyama J: Phylogenetic divergence of the entomophthoralean fungi: evidence from nuclear $18 \mathrm{~S}$ ribosomal RNA gene sequences. Mycologia 1995, 87(2):203-209.

9. Tanabe Y, O'Donnell K, Saikawa M, Sugiyama J: Molecular phylogeny of parasitic Zygomycota (Dimargaritales, Zoopagales) based on nuclear small subunit ribosomal DNA sequences. Molecular Phylogenetics and Evolution 2000, 16(2):253-262

10. James TY, Porter D, Leander CA, Vilgalys R, Longcore JE: Molecular phylogenetics of the Chytridiomycota supports the utility of ultrastructural data in chytrid systematics. Canadian Journal of BotanyRevue Canadienne De Botanique 2000, 78(3):336-350[http://www. nrcresearchpress.com/doi/abs/10.1139/b00-009].

11. Berbee ML, Taylor JW: Detecting morphological convergence in true fungi, using 185 rRNA gene sequence data. Biosystems 1992, 28(13):117-125.

12. Tanabe $Y$, Saikawa M, Watanabe MM, Sugiyama J: Molecular phylogeny of Zygomycota based on EF-1 alpha and RPB1 sequences: limitations and utility of alternative markers to rDNA. Mol Phylogen Evol 2004 30(2):438-449.

13. Liu YJJ, Hodson MC, Hall BD: Loss of the flagellum happened only once in the fungal lineage: phylogenetic structure of Kingdom Fungi inferred from RNA polymerase II subunit genes. Bmc Evolutionary Biology 2006, 6.

14. Liu Y, Steenkamp ET, Brinkmann H, Forget L, Philippe H, Lang BF: Phylogenomic analyses predict sistergroup relationship of nucleariids and Fungi and paraphyly of zygomycetes with significant support. BMC Evol Biol 2009, 9.

15. James TY, Letcher PM, Longcore JE, Mozley-Standridge SE, Porter $\mathrm{D}$, Powell MJ, Griffith GW, Vilgalys R: A molecular phylogeny of the flagellated fungi (Chytridiomycota) and description of a new phylum (Blastocladiomycota). Mycologia 2006, 98(6):860-871.

16. Sasaya T, Koganezawa H: Molecular analysis and virus transmission tests place Olpidium virulentus, a vector of Mirafiori lettuce big-vein virus and tobacco stunt virus, as a distinct species rather than a strain of Olpidium brassicae. Journal of General Plant Pathology 2006, 72:20-25.

17. Sparrow FK: Aquatic Phycomycetes. Ann Arbor: The University of Michigan Press; 21960

18. Karling JS: Chytridiomycetarum Iconographia. Monticello, NY: Lubrecht \& Cramer; 1977.

19. Dick MW: Straminipilous fungi: systematics of the peronosporomycetes, including accounts of the marine straminipilous protists, the plasmodiophorids, and similar organisms. Dordrecht: Kluwer Academic Publishers; 2001

20. Kim E, Graham LE: EEF2 analysis challenges the monophyly of Archaeplastida and Chromalveolata. Plos One 2008, 3(7)
21. Hui E, Rochon D: Evaluation of the roles of specific regions of the Cucumber necrosis virus coat protein arm in particle accumulation and fungus transmission. Journal of Virology 2006, 80(12):5968-5975.

22. Rochon D, Kakani K, Robbins M, Reade R: Molecular aspects of plant virus transmission by Olpidium and plasmodiophorid vectors. Annual Review of Phytopathology 2004, 42:211-241.

23. Letcher PM, Powell MJ, Churchill PF, Chambers JG: Ultrastructural and molecular phylogenetic delineation of a new order, the Rhizophydiales (Chytridiomycota). Mycological Research 2006, 110:898-915.

24. Temmink JHM, Campbell RN: The ultrastructure of Olpidium brassicae. II. Zoospores. Canadian Journal of Botany 1969, 47(2):227.

25. Lange L, Olson LW: The zoospore of Olpidium brassicae. Protoplasma 1976, 90(1-2):33-45.

26. Lange L, Olson LW: The flagellar apparatus and striated rhizoplast of the zoospore of Olpidium brassicae. Protoplasma 1976, 89(3-4):339-351.

27. Lange L, Olson LW: The zoospore of Olpidium radicale. Transactions of the British Mycological Society 1978, 71(AUG):43-55

28. Lange L, Olson LW: The uniflagellate phycomycete zoospore. Dansk Botanisk Arkiv 1979, 33(2):1-95.

29. Barr DJS, Hadland-Hartmann VE: Zoospore ultrastructure of Olpidium cucurbitacearum (Chytridiales). Canadian Journal of Botany-Revue Canadienne De Botanique 1977, 55(24):3063-3074.

30. Barr DJS, Hadland-Hartmann VE: Zoospore ultrastructure of Olpidium brassicae and Rhizophlyctis rosea. Canadian Journal of Botany-Revue Canadienne De Botanique 1977, 55(9):1221-1235.

31. Barr DJS: An outline for the reclassification of the Chytridiales, and for a new order, the Spizellomycetales. Canadian Journal of Botany-Revue Canadienne De Botanique 1980, 58(22):2380-2394.

32. Tanabe $Y$, Watanabe MM, Sugiyama J: Evolutionary relationships among basal fungi (Chytridiomycota and Zygomycota): Insights from molecular phylogenetics. Journal of General and Applied Microbiology 2005, 51(5):267-276.

33. Voigt K, Wöstemeyer J: Phylogeny and origin of 82 zygomycetes from all 54 genera of the Mucorales and Mortierellales based on combined analysis of actin and translation elongation factor EF-1 alpha genes. Gene 2001, 270(1-2):113-120.

34. Helgason T, Watson IJ, Young JPW: Phylogeny of the Glomerales and diversisporales (Fungi: Glomeromycota) from actin and elongation factor 1-alpha sequences. Fems Microbiology Letters 2003, 229(1):127-132.

35. Hesseltine CW, Ellis JJ: Mucorales. In The Fungi, an Advanced TreatiseVolume INB, A Taxonomic Review with Keys: Basidiomycetes and Lower Fungi. Edited by: Ainsworth GC, Sparrow FK, Sussman AS. San Francisco: Academic Press Inc:i 1973:187-217.

36. Beakes GW, Sekimoto S: The evolutionary phylogeny of oomycetes insights gained from studies of holocarpic parasites of algae and invertebrates. In Oomycete genetics and genomics: biology, plant and animal interactions, and toolbox. Edited by: Kamoun S, Lamour KH. NJ: John Wiley 2009:1-24.

37. Corradi N, Keeling PJ: Microsporidia: a journey through radical taxonomical revisions. Fungal Biology Reviews 2009, 23(1-2):1-8

38. Lee SC, Corradi N, Byrnes EJ, Torres-Martinez S, Dietrich FS, Keeling PJ, Heitman J: Microsporidia Evolved from Ancestral Sexual Fungi. Current Biology 2008, 18(21):1675-1679.

39. Koestler T, Ebersberger I: Zygomycetes, Microsporidia, and the Evolutionary Ancestry of Sex Determination. Genome Biology and Evolution 2011, 3:186-194

40. Held AA: Encystment and germination of the parasitic chytrid Rozella allomycis on host hyphae. Canadian Journal of Botany-Revue Canadienne De Botanique 1973, 51(10):1825.

41. O'Donnell KL: Zygomycetes in Culture. Palfrey Contributions in Botany No. 2. Athens, Georgia: Department of Botany, University of Georgia; 1979

42. Picard KT, Letcher PM, Powell MJ: Rhizidium phycophilum, a new species in Chytridiales. Mycologia 2009, 101(5):696-706

43. Campbell RN, Sim ST, Lecoq H: Virus transmission by host specific strains of Olpidium bornovanus and Olpidium brassicae. European Journal of Plant Pathology 1995, 101(3):273-282.

44. Hartwright LM, Hunter PJ, Walsh JA: A comparison of Olpidium isolates from a range of host plants using internal transcribed spacer sequence analysis and host range studies. Fungal Biol 2010, 114(1):26-33.

45. Hoffmann K, Discher S, Voigt K: Revision of the genus Absidia (Mucorales, Zygomycetes) based on physiological, phylogenetic, and morphological 
characters; thermotolerant Absidia spp. form a coherent group, Mycocladiaceae fam. nov. Mycological Research 2007, 111:1169-1183.

46. Rambaut A: Se-Al: Sequence Alignment Editor [http://tree.bio.ed.ac.uk/ software/seal/]. Edinburgh, UK: Institute of Evolutionary Biology, University of Edinburgh; 2.02002.

47. Abascal F, Zardoya R, Posada D: ProtTest: selection of best-fit models of protein evolution. Bioinformatics 2005, 21(9):2104-2105.

48. Stamatakis A: RAxML-VI-HPC: Maximum likelihood-based phylogenetic analyses with thousands of taxa and mixed models. Bioinformatics 2006 22(21):2688-2690.

49. Miller MA, Pfeiffer W, Schwartz T: Creating the CIPRES Science Gateway for inference of large phylogenetic trees. Proceedings of the Gateway Computing Environments Workshop (GCE): 14 Nov. 2010 2010; New Orleans, LA 2010, 1-8.

50. Huelsenbeck JP, Ronquist F: MRBAYES: Bayesian inference of phylogenetic trees. Bioinformatics 2001, 17(8):754-755.

51. Rambaut A, Drummond AJ: Tracer: MCMC Trace Analysis Tool. Edinburgh, UK: Institute of Evolutionary Biology, University of Edinburgh; 1.5.0 2007 [http://tree.bio.ed.ac.uk/software/tracer/].

52. Shimodaira $\mathrm{H}$, Hasegawa M: Multiple comparisons of log-likelihoods with applications to phylogenetic inference. Molecular Biology and Evolution 1999, 16(8):1114-1116.

53. Shimodaira $\mathrm{H}$ : An approximately unbiased test of phylogenetic tree selection. Systematic Biology 2002, 51(3):492-508.

54. Shimodaira $\mathrm{H}$, Hasegawa M: CONSEL: for assessing the confidence of phylogenetic tree selection. Bioinformatics 2001, 17(12):1246-1247.

55. Swofford DL: PAUP*: Phylogenetic Analysis using Parsimony (*and other, methods). Version 4. Sunderland, Mass.: Sinauer Associates; 1998.

56. Maddison DR, Maddison WP: MacClade. Sunderland: Sinauer; 4.082005 [http://macclade.org/macclade.html].

57. Maddison WP, Maddison DR: Mesquite: a modular system for evolutionary analysis., 2.752011 [http://mesquiteproject.org].

doi:10.1186/1471-2148-11-331

Cite this article as: Sekimoto et al:: A multigene phylogeny of Olpidium and its implications for early fungal evolution. BMC Evolutionary Biology 2011 11:331

\section{Submit your next manuscript to BioMed Central and take full advantage of:}

- Convenient online submission

- Thorough peer review

- No space constraints or color figure charges

- Immediate publication on acceptance

- Inclusion in PubMed, CAS, Scopus and Google Scholar

- Research which is freely available for redistribution

Submit your manuscript at www.biomedcentral.com/submit 